\title{
Grey Game Model for Energy Conservation Strategies
}

\author{
Si-Huan Li, ${ }^{1,2}$ Wei-Guo Zhang, ${ }^{1,3}$ and Lian-Sheng Tang ${ }^{4}$ \\ ${ }^{1}$ College of Economics \& Business Administration, Chongqing University, Chongqing 400044, China \\ ${ }^{2}$ School of Business, Huaihua University, Huaihua, Hunan 418000, China \\ ${ }^{3}$ College of Economics and Management, Southwest University, Chongqing 400715, China \\ ${ }^{4}$ School of Economics and Management, Ningbo University of Technology, Ningbo 315000, China
}

Correspondence should be addressed to Wei-Guo Zhang; wgzhang@cqu.edu.cn

Received 15 January 2014; Accepted 30 January 2014; Published 2 April 2014

Academic Editor: Jian-Wen Peng

Copyright (C) 2014 Si-Huan Li et al. This is an open access article distributed under the Creative Commons Attribution License, which permits unrestricted use, distribution, and reproduction in any medium, provided the original work is properly cited.

A grey game model is constructed for enterprise carbon emissions reduction and government policies on energy conservation, which explains the interaction equilibrium strategies between government and enterprises with resource constraints. The MATLAB tools are used to simulate the game process, and the result shows that the optimal strategy is consistent with the operation result. Finally, macroscopic countermeasures and suggestions are proposed for government and enterprise.

\section{Introduction}

Under the guidance of the energy saving and emission reduction during the 12th five-year plan, China has made remarkable achievements. However, series problems still exit, such as the insufficiency of self-recognition, the slowness of industrial restructuring progress, the lower efficiency utilization of energy, the imperfect of policy mechanism, and the weakness of foundation work. According to the government report, the highway transportation and air transportation have made the worst impact on the environment [1]. In China, transportation industry, as the most important constituent of logistics, is the second carbon emission resource which, next to oil consumption of manufacturing, ranked as the key project in energy conservation and emission reduction [2]. In order to achieve energy restriction and relieve the pressure of recourses and environment, it is essential to enhance carbonization emission reduction and improve the efficiency of energy conservation.

Most researchers focus on the logistics calculation and carbon emission reduction. Waisman et al. proposed the complementary framework of carbon price. It significantly reduced the carbon emission in long-term transportation, thus slowing down the increase of carbon price [3]; Rizet et al. calculated the amount of carbon emission in different supply chains by using the genetic algorithm method [4]; Dekker et al. reviewed the integrated logistics in green logistics and environmental aspects in production [5]; Zhao et al. analyzed the endogenous transaction cost of the carbon emission in industry and constructed a low carbonization location mode of multiple distribution centers [6]. Chinese researchers' studies concentrate on influential factors of the logistics industry development and evolution, which belong to qualitative research focus on the influential factors in energy conservation and emission reduction. Tang et al. constructed a logistics dynamics model of energy conservation and emission reduction [7]. The inherent relationship between enterprise and government is neglected according to the past literatures and so is the balance of interest impacts with market information. The price policies, finance, and taxation about energy conservation and emission reduction are not carried out perfectly in logistics. The mechanism of incentive and restriction is not sound enough to drive the innovation sufficiently. Most enterprises lack endogenous power for the cost of energy conservation and emission reduction. Besides, the government cannot know well the logistics of enterprises' energy conservation and emission reduction. The research about above is particularly important for government and enterprises. For the main participant's information is unsymmetrical, the game between government and enterprise is highly uncertain, which is the exact research area of Grey System Theory [8]. Wu and Chang applied this theory to 
the study of relationship between manufacturing enterprise and environment cost. Grey method is the most influential production management tool in evaluating various factors of environmental costs $[9,10]$.

In order to provide policy references for energy saving and emission reducing, a grey game model is constructed to mobilize the endogenous dynamic of enterprise, improve the high consumption and high emissions of logistics industry, and promote sustainable economic development. Maximizing benefits optimal strategies and measures can be expected with the balance of overall performance, and the rationality and validity of model are verified with simulation method.

\section{The System Description and Theoretical Assumptions}

When energy conservation and emissions reduction are proposed, government and enterprise constitute an entia of contradictions; both choose the optimal strategy to maximize their interests with game. Tax policy, as a market-oriented incentive policy model of environmental and governance policies in China, is the most important ways. As an implementation policy, appropriating subsidy cuts or rewards to enterprises' effort have slowed down the negative effects on market competition ability and encouraged enterprises to take measures to reduce carbon emissions, which should be the government's responsibility. In condition of asymmetric market information, government tends to monitor the transportation enterprise of energy conservation and emissions reduction, and transportation enterprise likely tries its best to play endogenous dynamic and the maximization of interests. Therefore, the following assumptions can be made.

First, the study is restricted to a closed economy, assuming that both game sides are risk-neutral ideal agents; involve more transportation industry links, considering the complexity of carbon emissions statistics. Carbon tax that the transportation enterprise paid embodied enterprise total revenue tax.

Second, related departments of government usually formulate relevant laws, regulations, and provisions. There are two action strategies for government- "carbon tax" and "no carbon tax" policy. The government interests represent social welfare to a certain extent. Considering carbon tax, the government should pay tax collecting costs. Since the transportation enterprises intend to evade taxes, the government's tax collecting cost is not enough to implement emission cost; so does the tax cost of enterprise emissions cutting. The implementation for transportation enterprises should offer certain subsidy cuts or rewards, and some do not make the implementation without a certain degree of punishment to enterprise emission reduction.

Third, for transportation enterprise there are two strategies - "reduction" and "not emissions-cutting". When emission cutting is performed, transport companies will pay a certain cost and will get government subsidies at the same time; if not, enterprises will be affected by a certain degree of punishment.
Fourth, assuming that government and enterprises' information are incomplete and asymmetric (grey). In order to maximize the benefit, transportation enterprise will hide the confidential business information. And the macrostrategy that the government adopts is also uncertain. So the game model belongs to the grey game.

\section{A Grey Game Model of Government and Transportation Enterprise Energy Conservation}

The Grey Game Theory is used to research the cooperation of government and company. Assuming government is a partner 1, and transportation Company is participants 2 . Based on the assumptions and theoretical basis, the notation conventions are as follows:

\section{$L:$ Total revenue transport companies. \\ C: Cost of energy saving enterprises.}

$M$ : Fine of the government gives companies, when enterprises do not perform energy conservation.

$U$ : Social utility of government, when companies do not perform energy conservation policy.

$U^{\prime}$ : Social utility of government, when companies perform energy conservation policy.

$C_{1}$ : Cost of government revenue, when companies perform energy conservation policy.

$C_{2}$ : Cost of government revenue, when companies do not perform energy conservation policy.

$\gamma$ : Subsidy rate of government to give companies incentives emissions, when companies perform energy conservation policy.

$\omega$ : Rate of carbon emissions for the government imposed transport companies.

$\pi_{1}(\otimes), \pi_{2}(\otimes):$ The expected profit of government and enterprises, when the government imposes a carbon tax, transportation companies perform reduction task, respectively.

$\pi_{1}(\otimes)^{\prime}, \pi_{2}(\otimes)^{\prime}$ : The expected profit of government and enterprises, when the government imposes a carbon tax, transportation companies do not perform reduction task, respectively.

$\pi_{2}(\otimes)^{\prime \prime}, \pi_{2}(\otimes)^{\prime \prime}$ : The expected profit of government and enterprises, when the government does not impose a carbon tax, transportation companies perform reduction task, respectively. 
TABLE 1: A grey profit and loss matrix of government and transportation companies.

\begin{tabular}{lcc}
\hline & \multicolumn{2}{c}{ Transportation companies } \\
& Performed reduction & Not performed reduction \\
\hline Government & & \\
Carbon tax & $\pi_{1}(\otimes), \pi_{2}(\otimes)$ & $\pi_{1}(\otimes)^{\prime}, \pi_{2}(\otimes)^{\prime}$ \\
No carbon $\operatorname{tax}$ & $\pi_{1}(\otimes)^{\prime \prime}, \pi_{2}(\otimes)^{\prime \prime}$ & $U, L$ \\
\hline
\end{tabular}

We can get

$$
\begin{gathered}
\pi_{1}(\otimes) \in\left[U^{\prime}-C_{1}, U^{\prime}-C_{1}-\gamma L+\omega L\right], \\
\pi_{2}(\otimes) \in[L-C, L-C+\gamma L-\omega L], \\
\pi_{1}(\otimes)^{\prime} \in\left[U-C_{2}+M, U-C_{2}+\omega L+M\right], \\
\pi_{2}(\otimes)^{\prime} \in[L-\omega L-M, L-M], \\
\pi_{1}(\otimes)^{\prime \prime} \in\left[U^{\prime}-\gamma L, U^{\prime}\right], \\
\pi_{2}(\otimes)^{\prime \prime} \in[L-C, L+\gamma L-C] .
\end{gathered}
$$

Government and transportation companies grey game matrix is given, as shown in Table 1 .

\section{Analysis of the Grey Game Model}

\subsection{Position Degree Analysis of Grey Game Model}

Proposition 1. Transportation companies perform tasks associated with the reduction of subsidies granted by the government, when the government imposes a carbon tax. When $\gamma L<$ $2(C-M)$, so $\pi_{2}(\otimes)^{\prime}>\pi_{2}(\otimes)$, and transportation companies tend not to perform reduction task.

Assume $\pi_{2}(\otimes) \in\left[a_{2}, b_{2}\right]=[L-C, L-C+\gamma L-\omega L]$, $\pi_{2}(\otimes)^{\prime} \in\left[a_{2}^{\prime}, b_{2}^{\prime}\right]=[L-\omega L-M, L-M]$, so

superiority position degree of grey number $\pi_{2}(\otimes)^{\prime}$ with respect to grey number $\pi_{2}(\otimes)[11]: S P D=\left(b_{2}^{\prime}-b_{2}\right) /\left(b_{2}^{\prime}-\right.$ $\left.a_{2}^{\prime}\right)=(-M+C-\gamma L+\omega L) / \omega L$,

inferior position degree of grey number $\pi_{2}(\otimes)^{\prime}$ with respect to grey number $\pi_{2}(\otimes): I P D=-\left(a_{2}-a_{2}^{\prime}\right) /\left(b_{2}^{\prime}-\right.$ $\left.a_{2}^{\prime}\right)=(C-\omega L-M) / \omega L$.

If $\gamma L<2(C-M)$, then: SPD $+I P D=(-\gamma L+2 \omega L) / \omega L>0$, so $\pi_{2}(\otimes)^{\prime}>\pi_{2}(\otimes)$.

Proposition 2. When transportation enterprise's reduction task is not performed, in order to get the maximum benefit, carbon tax is $\omega L>2\left(C_{2}-M\right)$.

Assume $\pi_{1}(\otimes)^{\prime} \in\left[a_{1}^{\prime}, b_{1}^{\prime}\right]=\left[U-C_{2}+M, U-C_{2}+\omega L+M\right]$; expected profit is a white number, namely, $[U, U]$ and $[L, L]$; if the government does not impose a carbon tax, transportation companies will not reduce emissions, and by contrast, the superiority position degree and the inferior position degree of carbon tax respectively are: $\left(-C_{2}+\omega L+M\right) / \omega L$ and $\left(-C_{2}+\right.$ $M) / \omega L$, If $\omega L>2\left(C_{2}-M\right)$, then $\left(-2 C_{2}+\omega L+2 M\right) / \omega L>0$.
The government impose a carbon tax is the superiority grey number.

Proposition 3. If $\gamma L>2(C-M), 2\left(C_{2}-M\right)<\omega L<2 C_{1}$, then $\pi_{1}(\otimes)>\pi_{1}(\otimes)^{\prime \prime}, \pi_{2}(\otimes)>\pi_{2}(\otimes)^{\prime}$, and the government imposes a carbon tax, and transportation companies perform reduction task.

Similarly, apply the steps for Proposition 2, to get the superiority position degree and the inferior position degree of $\pi_{1}(\otimes)$ with respect to $\pi_{1}(\otimes)^{\prime \prime}:\left(\omega L-\gamma L-C_{1}\right) /(\omega L-\gamma L)$ and $\left(-C_{1}+\gamma L\right) /(\omega L-\gamma L)$. Furthermore, under Proposition 2, if $2\left(C_{2}-M\right)<\omega L<2 C_{1}$, then the position degree of $\pi_{1}(\otimes)$ with respect to $\pi_{1}(\otimes)^{\prime \prime}:\left(\omega L-2 C_{1}\right) /(\omega L-\gamma L)>0$. It is the superiority grey number. Furthermore, under Proposition 1, if $\gamma L>2(C-M)$, then the position degree of $\pi_{2}(\otimes)$ with respect to $\pi_{2}(\otimes)^{\prime}$ is the superiority grey number. So $\pi_{1}(\otimes)>\pi_{1}(\otimes)^{\prime \prime}$, and $\pi_{2}(\otimes)>\pi_{2}(\otimes)^{\prime}$.

The above theorem demonstrates that the game equilibrium cannot be reached when the benefit sharing mechanism of two parts is imperfect and the information is incomplete or asymmetric. With the increasing subsidies to cut emissions for transportation enterprises, some reasonable carbon tax is beneficial to urge enterprises to execute emission reduction policy spontaneously. The possible equilibrium strategies and conditions have been analyzed below.

\subsection{Pure Strategy Equilibrium Analysis of the Grey Game Model}

(1) The equilibrium conditions of policy, when government imposes a carbon tax and transportation companies perform reduction task, is

government's strategy: $U^{\prime}-C_{1}+\omega L-\gamma L>U$, then $\gamma-\omega<\left(U^{\prime}-U-C_{1}\right) / L$;

transportation company's strategy: $L-\omega L+\gamma L-$ $C>L-\omega L-M$, then $\gamma>(C-M) / L$.

(2) The equilibrium conditions of the policy, when the government does not impose a carbon tax and transportation companies perform reduction task, is

government's strategy: $U^{\prime}-\gamma L>U-C_{2}+\omega L+M$, then $\gamma+\omega<\left(U^{\prime}-U+C_{2}-M\right) / L$;

transportation company's strategy: $L+\gamma L-C>$ $L$, then $\gamma>C / L$.

(3) The equilibrium conditions of the policy, when the government imposes a carbon tax, transportation companies do not perform reduction task, is

government's strategy: $U-C_{2}+\omega L+M>U$, then $\omega>\left(C_{2}-M\right) / L$;

transportation company's strategy: $L-\omega L-M>$ $L-\omega L+\gamma L-C$, then $\gamma<(C-M) / L$. 
(4) The equilibrium conditions of the policy, when the government does not impose a carbon tax, transportation companies do not perform reduction task, is

government's strategy: $U>U-C_{2}+\omega L+M$, then $\omega<\left(C_{2}-M\right) / L$;

government's strategy: $L>L+\gamma L-C$, then $\gamma<$ $C / L$.

4.3. Mixed Strategy Equilibrium Analysis of the Grey Game Model. When it satisfies the three equations at the same time, $\gamma+\omega<\left(U^{\prime}-U+C_{2}-M\right) / L,(C-M) / L<$ $\gamma<C / L, \omega>\left(C_{2}-M\right) / L$, the Game Theory will form a cyclic one that the government collects the carbon tax or not, and the transportation enterprise executes the emissionreduction task or not. The equilibrium solution of this game theory will be a mixed strategy, supposing the carbon tax will be collected by the government in probability of $\lambda$, and the transportation enterprise will choose not to do emission reduction in probability of $\theta$. To analyze the optimal behavior, both sides choices are, respectively, as follows.

(1) Analysis of the Government's Optimal Choice. The government's expected utility is

$$
\begin{aligned}
U_{g}=\lambda & {\left[\theta\left(U-C_{2}+\omega L+M\right)\right.} \\
& \left.+(1-\theta)\left(U^{\prime}-C_{1}+\omega L-\gamma L\right)\right] \\
& +(1-\lambda)\left[\theta \cdot U+(1-\theta)\left(U^{\prime}-\gamma L\right)\right], \\
\frac{d U_{g}}{d \lambda}= & -\theta C_{2}+\theta M-C_{1}+\omega L+\theta C_{1}=0
\end{aligned}
$$

then,

$$
\theta=\frac{C_{1}-\omega L}{C_{1}-C_{2}+M} .
$$

This formula indicates that if the transportation enterprises refuse performing emission reduction at probability of less than $\theta$, the effectiveness of the government' choice for noncarbon tax will be greater than levying the carbon tax; the government's optimal choice is not levying carbon tax. When the probability of the transportation enterprises' not performing emission reduction exceeds $\theta$, then the government's optimal choice is levying carbon tax. While once this Probability is equal to $\theta$, it becomes indifferent to the government's decision for the taxation.

(2) Analysis of Transportation Companies. Transportation companies' expected utility is

$$
\begin{gathered}
U_{l}=\theta[\lambda(L-\omega L-M)+(1-\lambda) L] \\
+(1-\theta)[\lambda(L-\omega L+\gamma L-C) \\
+(1-\lambda)(L+\gamma L-C)], \\
\frac{d U_{l}}{d \theta}=-\lambda M-\gamma L+C=0 .
\end{gathered}
$$

Then,

$$
\lambda=\frac{\gamma L-C}{M} .
$$

It shows that when the government's probability of collecting carbon tax is smaller than $\lambda$, the preferential strategies for transportation enterprises is not performing emission reduction; while if the probability for carbon tax is greater than $\lambda$, then the preferential strategies for the transportation enterprises is performing emission reduction. When the probability is equal to $\lambda$, the effectiveness for both performing emission reduction or not is the same.

4.4. Nonlinear Programming Solution of the Grey Game Model. By the functions equations (2) and (5) for these (4) and (6), the following can be gotten: $U_{g}=f(\gamma, \omega) ; U_{l}=f(\gamma, \omega)$.

Grey game model optimal solution can be transformed into multiparameter and multiobjective nonlinear programming problems:

$$
\text { s.t. } U_{g}=f(\gamma, \omega) ; \quad U_{l}=f(\gamma, \omega)
$$

constraint condition:

$$
\begin{aligned}
2(C-M) & <\gamma L<C, \\
2\left(C_{2}-M\right) & <\omega L<2 C_{1}, \\
0 & <\gamma, \omega<1 .
\end{aligned}
$$

To reach optimal, the multiobjective function is converted into single objective function. Assuming the right weight, respectively, $U_{g}$ and $U_{l}$ are $\alpha$ and $\beta$, and $\alpha+\beta=1$; $0<\alpha<1 ; 0<\beta<1$ :

$$
\begin{array}{r}
\text { s.t. } \max U=\alpha U_{g}+\beta U_{l}, \\
2(C-M)<\gamma L<C, \\
2\left(C_{2}-M\right)<\omega L<2 C_{1}, \\
0<\gamma, \omega<1 .
\end{array}
$$

\section{Simulation and Analysis}

5.1. MATLAB Model Simulation. According to the grey game model, a MATLAB tool is used for transport enterprise of energy saving strategy simulation. Assuming $L=30, C=12$, $M=10, U=50, U^{\prime}=60, C_{1}=8$, and $C_{2}=13$, Then multiobjective linear programming functions is transferred into a single objective nonlinear programming function as follows:

$$
\begin{aligned}
& \text { s.t. } \quad \max U= \alpha(44+18 \gamma+60 \omega-180 \gamma \omega) \\
&+\beta(56.4-108 \omega-66 \gamma+270 \omega \gamma) \\
& 0.13<\gamma<0.4 \\
& 0.2<\omega<0.53 \\
& \alpha+\beta=1, \quad 0<\alpha<1, \quad 0<\beta<1 .
\end{aligned}
$$




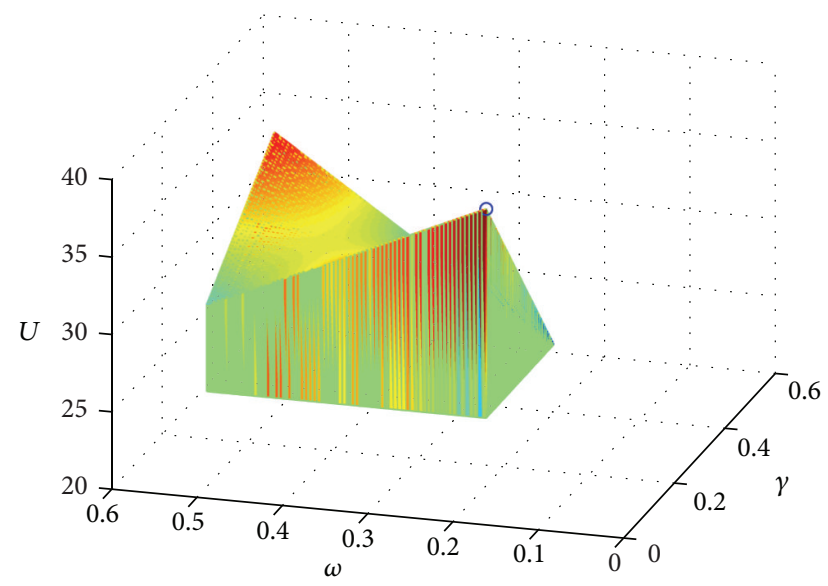

FIgURE 1: When $\alpha=0.1, \beta=0.9$, The weighted three-dimensional map system-wide revenue.

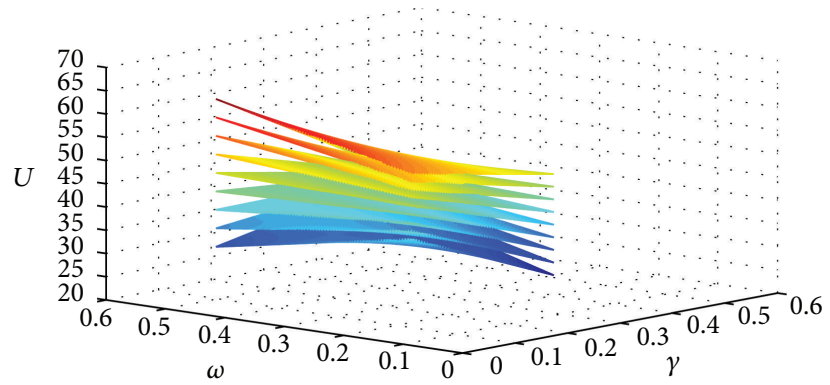

FIGURE 2: 9 kinds of weights assigned revenue under a system-wide weighted three-dimensional.

The weight of government' expected utility and transportation companies' expected utility is $\alpha=0.1,0.2, \ldots, 0.9$; $\beta=0.1,0.2, \ldots, 0.9 ; \alpha+\beta=1$. Figure 1 can be drawn. For the sake of brevity, only graphics when $\alpha=0.1$ and $\beta=0.9$ are shown; as can be seen the maximum points of benefit is $\gamma=$ $0.13, \omega=0.2$, and $U=37.9280$.

In order to compare the differences of different systemdimensional weight gains, 9 kinds of assignment case graphics are put into one (space), as shown in Figure 2.

With MATLAB program operation, 9 kinds of weight assignment system case of income statement can be drawn, as shown in Table 2.

The whole system weighted revenue trend is drawn with nine kinds of weight gains assignment case, as shown in Figure 3.

5.2. MATLAB Model Simulation Analysis. (1) Figure 1 shows that when $\alpha=0.1, \beta=0.9$, the maximum earnings are to be the only choice for transportation enterprise, achieving equilibrium $\gamma=0.13, \omega=0.2$; namely, the government subsidies and enterprise tax are able to implement the lower limit of energy conservation and emissions reduction policy constraints; the system revenue is the largest one.

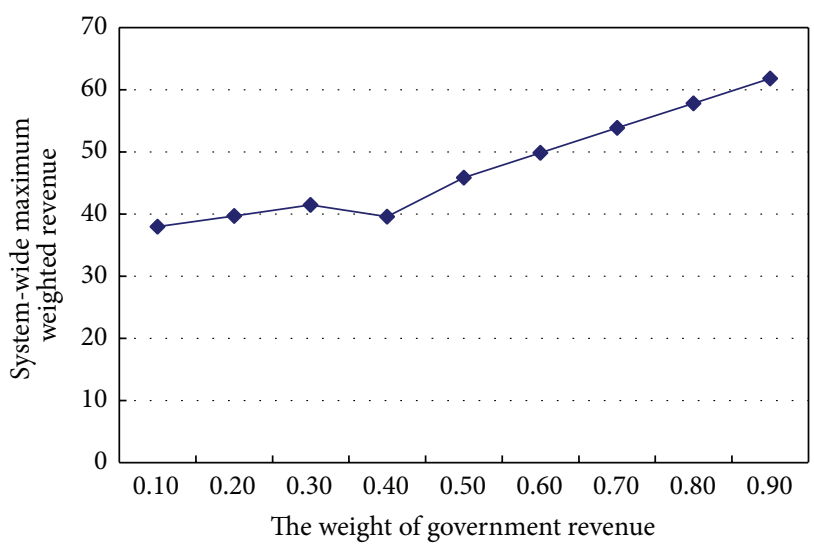

Figure 3: Different circumstances assignment system-wide maximum weighted revenue trend.

(2) From the three-dimensional graph (Figure 2), we can see the total system revenue forms numerous surfaces without cross point under the different weights. As the proportion of government revenue increases, surfaces gradually rise. It shows that the more share of the government's income in total revenue is, the greater the revenue of the whole system is, which shows that government should play a leading role. Enterprise energy conservation and emissions reduction policy should be made from the view of improving the whole social welfare allocation and maximizing value creation of the whole social-economic system.

(3) According to Table 2, when government imposed a carbon tax and transportation companies implemented energy conservation, $\gamma=0.13, \omega=0.53$, the system's total revenue gains the maximum is $U=61.7625(\alpha=0.9, \beta=$ 0.1 ). The maximum benefits can be obtained only when the government utility (i.e., the interests of society) weight is maximum. It illustrates that only government concentrates social forces with the aim of allocating optimal resources; the society utility maximization can be achieved. Therefore, the energy saving and emission reduction strategy for transportation enterprise should be made on the basis of such conditions where the government's macroeconomic policies need to play a guiding role in the socialist market economy system, formulate reasonable mechanism of energy conservation and emissions reduction, and fully mobilize the enthusiasm of enterprise.

(4) From the maximum value trend graph, it can be seen that system optimal value tends to increase according to the increasing government weight. However, there still exists a slight decline when the weight is 0.4 , where the number verification turns out to be an assignment question, which could be ignored; the increasing government weight leads to different results.

(5) It is to be seen when government levies the carbon tax and the enterprise of transportation takes energy-saving and emission-reduction measures, $\gamma=0.13, \omega=0.53$, and the optimal resolution will mainly be on the definition boundary. 
TABLE 2: The maximum weight gain system-wide assignment in different situations.

\begin{tabular}{lll}
\hline$\alpha=0.1, \beta=0.9$ & $\gamma=0.13, \omega=0.2$ & $U=37.9280$ \\
$\alpha=0.2, \beta=0.8$ & $\gamma=0.13, \omega=0.2$ & $U=39.6760$ \\
$\alpha=0.3, \beta=0.7$ & $\gamma=0.13, \omega=0.2$ & $U=41.4240$ \\
$\alpha=0.4, \beta=0.6$ & $\gamma=0.13, \omega=0.2$ & $U=39.5540$ \\
$\alpha=0.5, \beta=0.5$ & $\gamma=0.13, \omega=0.53$ & $U=45.8605$ \\
$\alpha=0.6, \beta=0.4$ & $\gamma=0.13, \omega=0.53$ & $U=49.8360$ \\
$\alpha=0.7, \beta=0.3$ & $\gamma=0.13, \omega=0.53$ & $U=53.8115$ \\
$\alpha=0.8, \beta=0.2$ & $\gamma=0.13, \omega=0.53$ & $U=57.7870$ \\
$\alpha=0.9, \beta=0.1$ & $\gamma=0.13, \omega=0.53$ & $U=61.7625$ \\
\hline
\end{tabular}

According to Proposition 3, $\gamma L=2(C-M), \omega L=2 C_{1}$, therefore, the optimal rate of tax return and compensation is $2(C-$ $M) / L$, and the optimal rate of carton $\operatorname{tax}$ is $2 C_{1} / L$.

\section{Concluding Remarks}

Apparently, it is necessary that the government supervises the enterprise and takes appropriate actions. The grey game model and the simulation method research analyzed game between government and enterprise and realized the maximum of social resources and whole society utility. Thus, government should consider formulating the transportation system and its implementation. Giving the transportation enterprise some bonus, it can motivate the enterprise to try to achieve the target by focusing on their technology and management to gain the maximum value.

\section{Conflict of Interests}

The authors declare that there is no conflict of interests regarding the publication of this paper.

\section{Acknowledgments}

This research was partially supported by the Major Research plan of the National Social Science Foundation of China (12\&ZD100) and Natural Science Foundation of Hunan Province of China (14JJ7074).

\section{References}

[1] J. P. Rodrigue, C. C. Tois, and B. Slack, The Geography of Transport Systems, Routledge, New York, NY, USA, 2nd edition, 2009.

[2] http://www.gov.cn/zwgk/2012-08/21/content_2207867.htm.

[3] H. D. Waisman, C. Guivarch, and F. Lecocq, "The transportation sector and low-carbon growth pathways: modeling urban, infrastructure, and spatial determinants of mobility," Climate Policy, vol. 13, pp. 106-129, 2013.

[4] C. Rizet, M. Browne, E. Cornelis, and J. Leonardi, "Assessing carbon footprint and energy efficiency in competing supply chains: review-case studies and benchmarking," Transportation Research D, vol. 17, no. 4, pp. 293-300, 2012.

[5] R. Dekker, J. Bloemhof, and I. Mallidis, "Operations Research for green logistics-an overview of aspects, issues, contributions and challenges," European Journal of Operational Research, vol. 219, no. 3, pp. 671-679, 2012.

[6] P. Zhao, B. Liu, L. Xu, and D. Wan, "Location optimization of multi-distribution centers based on low-carbon constraints," Discrete Dynamics in Nature and Society, vol. 2013, Article ID 427691, 6 pages, 2013.

[7] L. Tang, Y. Zeng, C. Wang, and D. Cao, “The logistics policy simulation of energy saving and emission reduction based on system dynamics," Systems Engineering, no. 6, pp. 87-94, 2013.

[8] K. Ohnishi and Y. Tomikawa, Coriolis flowmeter, US, 684 716.[P]. 2004-06.

[9] C. C. Wu and N. B. Chang, "Grey input-output analysis and its application for environmental cost allocation," European Journal of Operational Research, vol. 145, no. 1, pp. 175-201, 2003.

[10] C. C. Wu and N. B. Chang, "Corporate optimal production planning with varying environmental costs: a grey compromise programming approach," European Journal of Operational Research, vol. 155, no. 1, pp. 68-95, 2004.

[11] Z. G. Fang, Research on the grey game theory and its application in economy [Ph.D. thesis], Nanjing University of Aeronautics and Astronautics, Nanjing, China, 2007. 


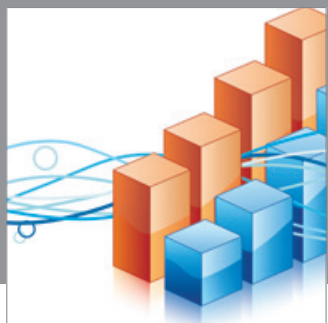

Advances in

Operations Research

mansans

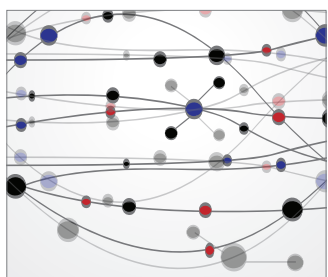

The Scientific World Journal
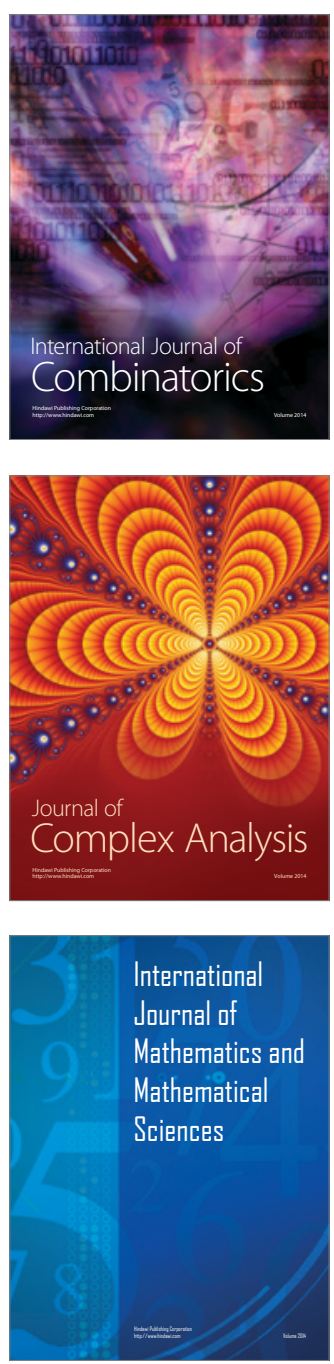
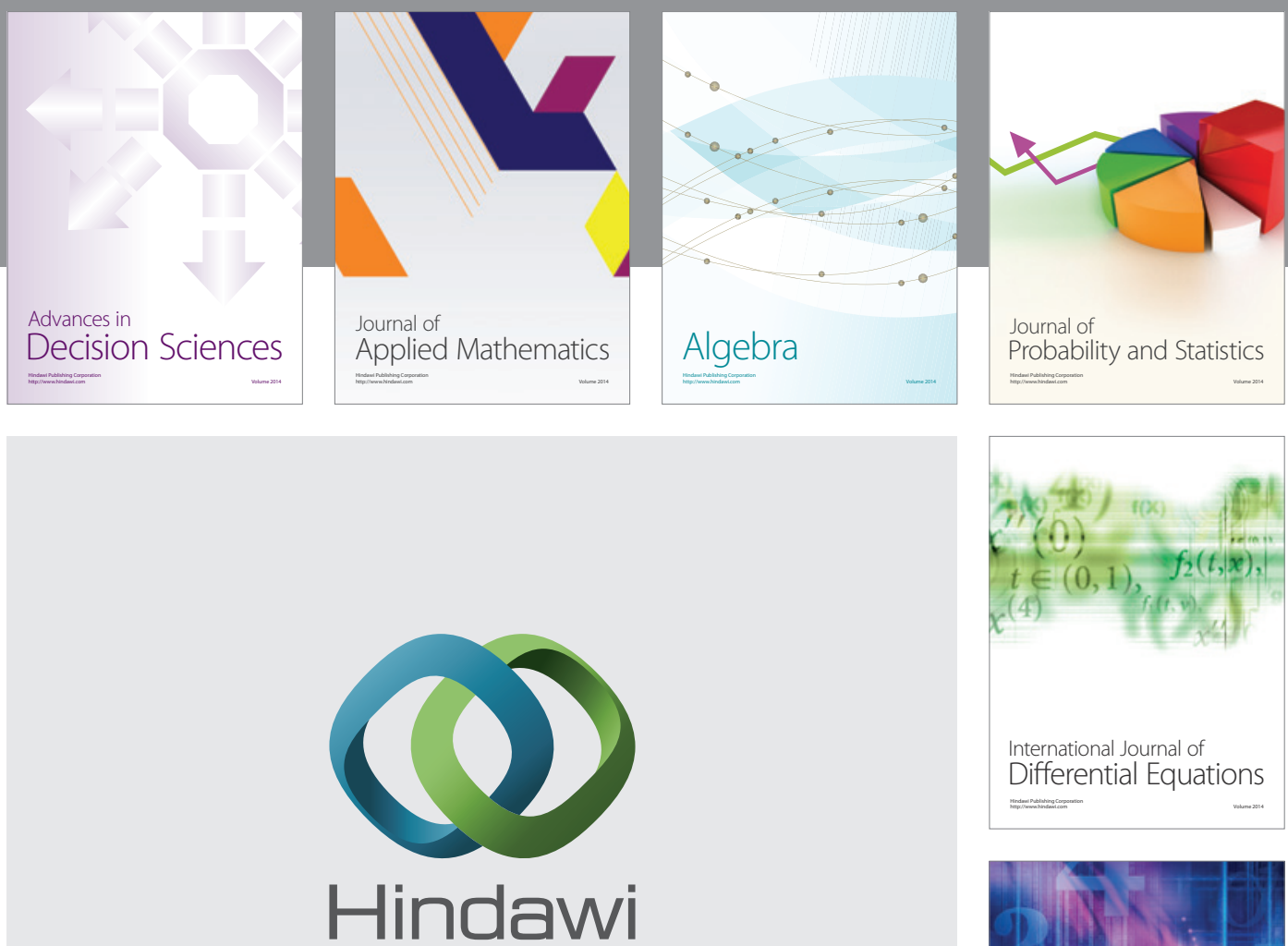

Submit your manuscripts at http://www.hindawi.com
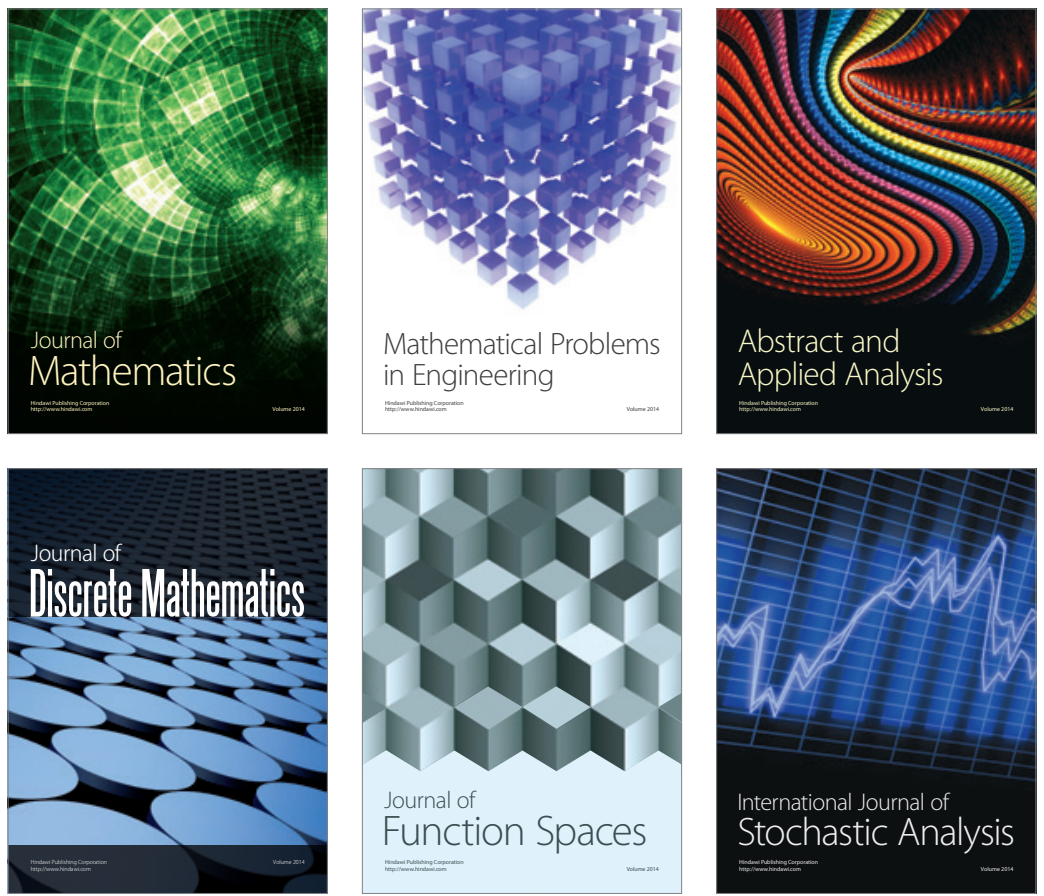

Journal of

Function Spaces

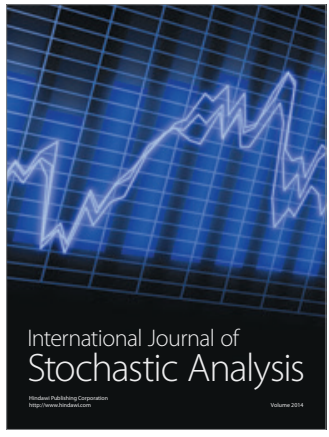

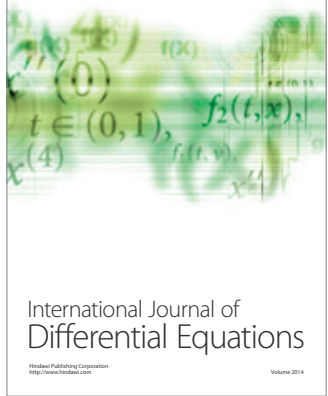
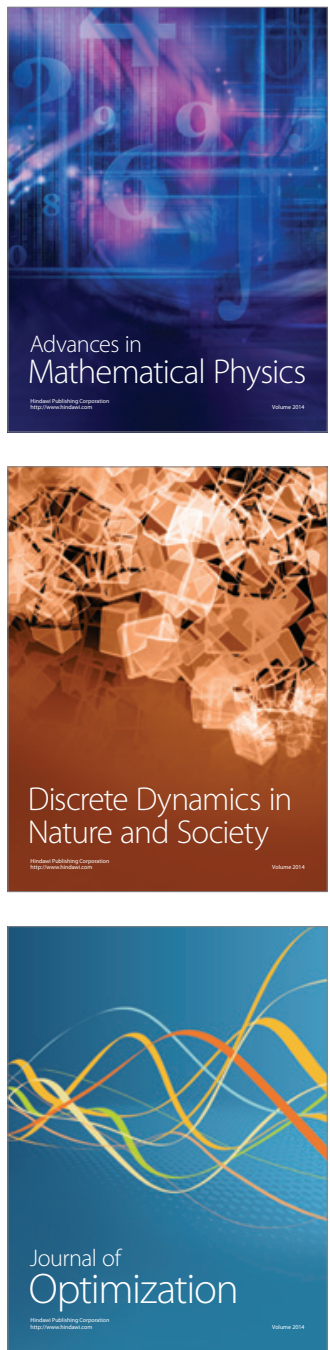